\title{
Importance of pre-mating nutritional and metabolic conditions for litter uniformity
}

\author{
J.G.M. Wientjes, N.M. Soede, H. van den Brand and B. Kemp \\ Adaptation Physiology Group, Wageningen University, Wageningen, The Netherlands
}

For piglet survival, as well as for piglet performance before and after weaning, high piglet birth weights and litter uniformity are crucial (Quiniou et al. 2002). Within-litter variation in birth weight seems to be the consequence of within-litter variation in early embryo development (Van der Lende et al. 1990), which in turn reflects variation in follicle and oocyte development (Pope et al. 1990). Insulin-stimulating sow diets before mating can improve litter uniformity (Van den Brand et al. 2006, 2009), probably through beneficial effects of insulin on IGF-1 and follicle development. Plasma insulin and IGF-1 levels and follicle development are also influenced by the metabolic state of the sow. Plasma insulin and IGF-1 levels and follicle development are suppressed in sows with severe body condition loss during lactation, and restoration of plasma insulin and IGF-1 levels and follicle development occurs in sows with a recovery period after weaning (Quesnel 2009). We studied in multiparous sows effects of (i) insulin-stimulating diets during the weaning-to-estrus interval (WEI) on follicle development and development and uniformity of pre-implantation embryos at day 10 of pregnancy (Wientjes et al. 2012a,b) and fetuses and placentas at day 42 of pregnancy; and (ii) premating conditions related with sow metabolic state during lactation (body condition loss) and after weaning (length of weaning-to-pregnancy interval; WPI) on litter uniformity at birth.

Multiparous sows $(\mathrm{n}=32)$ were fed an insulin-stimulating diet (dextrose plus lactose, both $150 \mathrm{~g} /$ day) at $4 \mathrm{~h}$-intervals or an isocaloric control diet at $12 \mathrm{~h}$-intervals during WEI. Total insulin secretion, absolute insulin levels and plasma IGF-1 levels were not affected by the dietary treatments, although contrasts were created in the insulin secretion patterns during WEI (6 short insulin peaks/day vs. 2 sustained insulin peaks/day). The dextrose plus lactose diet fed at $4 \mathrm{~h}$-intervals during WEI resulted in a lower pre-ovulatory LH surge ( $3.0 \mathrm{vs} .3 .7 \mathrm{ng} / \mathrm{ml}, P=0.03)$, smaller follicles at day 4 after weaning (6.1 vs. $6.5 \mathrm{~mm}, P=0.08$ ) and subsequently smaller corpora lutea (mean diameter: 9.6 vs. 10.0 $\mathrm{mm}, P=0.06$ ) and less developed embryos at day 10 of pregnancy (mean diameter: $6.4 \mathrm{vs} .7 .1 \mathrm{~mm}$, $P=0.07$ ) compared with the control diet fed at $12 \mathrm{~h}$-intervals. Independent of treatment, positive relations were found between mean insulin levels during WEI and subsequent progesterone levels $(\beta=0.27(\mathrm{ng} / \mathrm{ml}) /(\mu \mathrm{U} / \mathrm{ml}), P=0.05)$ and embryo development (mean diameter: $\beta=0.06 \mathrm{~mm} /(\mu \mathrm{U} /$ $\mathrm{ml}), P=0.09$ ), but not embryo uniformity at day 10 of pregnancy. Whether and how this results in a more uniform development of fetuses and piglets at later stages of pregnancy was the focus of a follow-up experiment, in which multiparous sows $(n=54)$ were isocalorically fed $(2 x /$ day $)$ an insulin-stimulating diet supplemented with dextrose plus corn starch (both 375 g/day or both 172 g/day) or a control diet during WEI. Postprandial insulin responses, both insulin peaks ( $<1 \mathrm{~h}$ after feeding) and long-term insulin level ( $\sim$ h after feeding), were successfully stimulated during WEI by the insulin-stimulating diets in a dose-dependent manner, but plasma IGF-1 levels during the first three days after weaning were not affected. Follicle development and subsequent development and uniformity of fetuses and placentas at day 42 of pregnancy were not affected by these insulinstimulating diets, nor related with plasma insulin and IGF-1 levels during WEI. Because uniformity of embryos or fetuses and placentas was not influenced by the insulin-stimulating diets during WEI, nor related with plasma insulin and IGF-1 levels during WEI, these experiments do not confirm that nutritionally increased plasma insulin and IGF-1 levels during only WEI can improve subsequent litter uniformity in multiparous sows. 
To study effects of pre-mating conditions related with sow metabolic state during lactation (body weight loss and backfat loss during lactation) and after weaning (length of WPI) on litter uniformity (SD and CV of birth weight), individual piglet birth weights (live born and stillborn) were determined at one farm. Litter uniformity at birth was significantly higher in sows with a WPI of $>21$ days and numerically higher in sows with a WPI between 8 and 21 days compared with sows with a WPI of $\leq 7$ days (Table 1 ). In sows with a regular WPI ( $\leq 7$ days; $n=808$ ), litter uniformity at birth was negatively and linearly related with body condition loss during previous lactation (of $26 \pm 3$ days). For example, a higher body weight loss during previous lactation $[\leq 3.5 \%(20 \%$ lowest class) vs. $>13 \%(20 \%$ highest class)] resulted in $+28 \mathrm{~g}$ in birth weight SD $(P=0.02)$. A higher backfat loss during previous lactation [ $\leq 2 \mathrm{~mm}(20 \%$ lowest class) vs. $>5 \mathrm{~mm}$ ( $20 \%$ highest class)] resulted in $+25 \mathrm{~g}$ in birth weight SD $(P=0.04)$ and $+1.8 \%$ in birth weight $\mathrm{CV}(P=0.05)$.

Table 1. Effects of weaning-to-pregnancy interval (WPI) on litter characteristics of total born piglets at birth (LSM \pm SEM).

\begin{tabular}{|c|c|c|c|c|c|}
\hline & $\begin{aligned} & W P I \\
& \leq 7 \text { days } \\
&\end{aligned}$ & $\begin{array}{c}\text { WPI } \\
8 \text { to } 21 \text { days }\end{array}$ & $\begin{array}{l}\text { WPI > } 21 \text { days } \\
+ \text { repeat breeders }\end{array}$ & SEM & $P$-value \\
\hline Number of litters, $n$ & 1,584 & 72 & 182 & & \\
\hline Total number born, $\mathrm{n}$ & $13.7^{\mathrm{a}}$ & $14.9^{b}$ & $14.4^{b}$ & 0.3 & $<0.01$ \\
\hline Mean birth weight ${ }^{*}, \mathrm{~g}$ & 1,428 & 1,438 & 1,431 & 17 & 0.83 \\
\hline SD of birth weight*, g & $310^{\mathrm{b}}$ & $291^{\mathrm{ab}}$ & $287^{\mathrm{a}}$ & 7 & $<0.01$ \\
\hline CV of birth weight ${ }^{*}, \%$ & $22.2^{\mathrm{b}}$ & $20.8^{\mathrm{ab}}$ & $20.5^{\mathrm{a}}$ & 0.5 & $<0.01$ \\
\hline
\end{tabular}

${ }^{*}$ Corrected for the effect of total number born; ${ }^{\text {ab }}$ Within rows, values lacking a common superscript differ $(P \leq 0.05)$.

To conclude, pre-mating conditions related with sow metabolic state can affect subsequent litter uniformity. Litter uniformity at birth was compromised by severe sow body condition loss during previous lactation and improved in sows with a prolonged WPI. These results confirm that litter uniformity at birth is already (partly) determined during the pre-mating period, likely related with (insufficient) restoration of follicle development. In contrast to previous studies, insulin-stimulating diets during WEI did not improve litter uniformity of embryos or fetuses and placentas in our multiparous sows. These inconsistent effects may be related with differences in sow parity, sow body condition loss during lactation and/or the period of feeding insulin-stimulating diets (lactation and/or WEI) among studies, and thereby differences in plasma IGF-1 levels and follicle development at weaning. These factors need further study.

\section{References}

Pope WF, Xie S, Broermann DM \& Nephew KP 1990 Causes and consequences of early embryonic diversity in pigs. Journal of Reproduction and Fertility Suppl. 40 251-260.

Quesnel H 2009 Nutritional and lactational effects on follicular development in the pig. Control of Pig Reproduction 8 121-134.

Quiniou N, Dagorn J \& Gaudré D 2002 Variation of piglets' birth weight and consequences on subsequent performance. Livestock Production Science 78 63-70.

Van den Brand H, Soede NM \& Kemp B 2006 Supplementation of dextrose to the diet during the weaning to estrus interval affects subsequent variation in within-litter piglet birth weight. Animal Reproduction Science 91 353-358.

Van den Brand H, Van Enckevort LCM, Van der Hoeven EM \& Kemp B 2009 Effects of dextrose plus lactose in the sows diet on subsequent reproductive performance and within litter birth weight variation. Reproduction in Domestic Animals 44 884-888.
Van der Lende T, Hazeleger W \& De Jager D 1990 Weight distribution within litters at the early foetal stage and at birth in relation to embryonic mortality in the pig. Livestock Production Science 26 53-65.

Wientjes JGM, Soede NM, Van den Brand H \& Kemp B 2012a Nutritionally induced relationships between insulin levels during the weaning-to-ovulation interval and reproductive characteristics in multiparous sows: I. Luteinizing hormone, follicle development, estrus and ovulation. Reproduction in Domestic Animals 47 53-61.

Wientjes JGM, Soede NM, Van den Brand H \& Kemp B 2012b Nutritionally induced relationships between insulin levels during the weaning-to-ovulation interval and reproductive characteristics in multiparous sows: II. Luteal development, progesterone and conceptus development and uniformity. Reproduction in Domestic Animals 47 62-68. 